\title{
Frequency and predictors of the Lupus Low Disease Activity State in Chinese patients with systemic lupus erythematosus: a prospective observational cohort study
}

\section{Dai Gao}

Peking University First Hospital https://orcid.org/0000-0002-7982-8112

\section{Yanjie Hao}

Peking University First Hospital

Lin Mu

Peking University First Hospital

\section{Wenhui Xie}

Peking University First Hospital

\section{Yong Fan}

Peking University First Hospital

\section{Lanlan Ji}

Peking University First Hospital

Zhuoli Zhang ( $\nabla$ zhuoli.zhang@126.com )

Peking University First Hospital https://orcid.org/0000-0002-6925-4960

\section{Research article}

Keywords: Systemic lupus erythematosus, Disease activity, Treatment target, Outcomes research, Cohort study

Posted Date: December 23rd, 2019

DOI: https://doi.org/10.21203/rs.2.19477/v1

License: (a) This work is licensed under a Creative Commons Attribution 4.0 International License. Read Full License 


\section{Abstract}

Background Systemic lupus erythematosus (SLE) is a chronic autoimmune disorder with significant risk of organ damage. Lupus Low Disease Activity State (LLDAS) was generated as a potential treatment target for SLE. Previous studies had validated that the maintenance of LLDAS can predict reduced damage accrual or flare. The objective of this study was to estimate the time to LLDAS and the predictors of time to LLDAS in our prospective observational cohort of Chinese patients with SLE.

Methods Patients were from Peking University First Hospital SLE cohort and those having not fulfilled LLDAS at enrolment were included in this study. The time to LLDAS and annual cumulative probabilities of LLDAS achievement were estimated by the Kaplan-Meier approach. The predictors of time to LLDAS were identified by univariate and multivariable Cox proportional hazards.

Results A total of 574 patients with SLE were included and $435(75.8 \%)$ of them achieved LLDAS during a median 4.2 years of follow-up. The median time to LLDAS was 19.0 months and the cumulative probabilities at $1,2,3,5$ and 10 years were $19.8 \%, 57.6 \%, 72.0 \%, 85.1 \%$ and $98.0 \%$, respectively. In multivariable Cox models, older age at disease onset, treatment-naïve and hydroxychloroquine prescription were found to be independent predictors of shorter time to LLDAS, after adjusted by daily prednisone dose, SLE Disease Activity Index 2000 and physician's global assessment. Finally, we developed a matrix model based on the identified independent predictors to present the time to LLDAS in patients with respective characteristics.

Conclusions Our study proved that LLDAS is attainable as an early treatment target for SLE in Chinese patients. The older age at disease onset, treatment-naïve and hydroxychloroquine prescription were independent predictors of shorter time to LLDAS.

\section{Background}

Systemic lupus erythematosus (SLE) is a challenging chronic autoimmune disorder with variable clinical manifestations. The survival rate of patients with SLE has got progressive improvement with early diagnosis and pharmacopoeia development over the past decades; however, the mortality of SLE is still twice of the general population [1-4].

Long-term observational studies have demonstrated that disease activity was positively associated with the risk of subsequent organ damage and mortality $[5,6]$. In accordance with these findings, remission and the lowest possible disease activity were set as the treatment targets of SLE in the treat-to-target recommendations released in 2014 [7].

Recently, a framework for remission in SLE has been established by a large international task force, however, the framework contained four different definitions and no specific definition of remission has been widely accepted by now [8]. Furthermore, the attainability and sustainability of these definitions were still in debate [9-13]. 
In contrast with remission, low disease activity state was more appropriate as an early treatment target with higher attainability and sustainability [12-19]. Among the definitions of low disease activity in SLE, the Lupus Low Disease Activity State (LLDAS) developed by Asia-Pacific Lupus Collaboration was wellvalidated and widely accepted [9-11, 20-22]. Previous studies had proved that the maintenance of LLDAS during follow-up was associated with a lower frequency of organ damage accrual or flare [14-16, 22-25]. Meanwhile, some studies had revealed the associated factors of maintaining LLDAS during follow-up $[14,15,22-26]$. However, most of these studies included the patients who had already achieved LLDAS at baseline, therefore, they were unable to analyse the attainability of LLDAS achievement from high or moderate disease activity to LLDAS.

Until now, the only one study which estimated the attainability of LLDAS was the Hopkins Lupus Cohort study consisting of Caucasian and African-American SLE patients [26]. Several studies found that Asians had significant differences with Caucasians in terms of disease activity, renal involvement, autoantibodypositive rate, organ damage rate and mortality rate [27-32]. Moreover, studies by Asia-Pacific Lupus Collaboration showed that the possibility of LLDAS $\geq 50 \%$ time during follow-up was lower in Asian population than that in Caucasians, though it did not reach statistical difference [22, 23]. No data about the attainability of LLDAS achievement in Asian ethnicity has been reported so far.

In this study, we estimated the time to LLDAS and the predictors of time to LLDAS in our prospective observational cohort of Chinese patients with SLE.

\section{Methods}

\section{Patients}

The Peking University First Hospital SLE (PKUFHS) cohort is a single-centre prospective observational cohort since 2007. Patients were diagnosed according to the revised American College of Rheumatology (ACR) criteria or the Systemic Lupus International Collaborating Clinics (SLICC) criteria. After the recruitment, patients were regularly followed up every 1 to 3 months when the disease was active, or every 3 to 6 months when the disease was stable, which was determined by the rheumatologists.

In this study, patients from the PKUFHS cohort recruited between January 2007 and December 2018 were included if they meet all of the following criteria: (a) did not fulfil LLDAS at baseline; (b) had no other connective tissue diseases except Sjogren's syndrome (SS) or antiphospholipid syndrome (APS), inflammatory arthropathy or other diseases exerting obvious effect on disease activity assessment and GCs tapering; (c) had at least 3 follow-up visits and 6 months of follow-up duration; and (d) had no interval of more than 12 months between two consecutive visits.

This study was approved by the ethics committee of Peking University First Hospital and all patients signed the informed consent at enrolment.

\section{Data collection}


Data were collected at outpatient visits and hospital admissions from January 2007 to June 2019. Gender, age at disease onset and disease duration were recorded with baseline manifestations, laboratories and complications, including SS and APS.

Age at disease onset was defined as the age when the symptom or laboratory abnormality related to SLE was initially presented. Disease duration was defined as the time from disease onset to the recruitment. Early SLE was defined when the disease duration was no more than 1 year. Treatment-naïve was defined as no previous glucocorticoid or immunosuppressants (IMs) therapy. Clinical manifestations and laboratories were defined and recorded with the reference of the SLE Disease Activity Index 2000 (SLEDAI-2K) [33, 34]. Additionally, nephritis was defined when either of proteinuria, haematuria, sterile pyuria or urinary casts was presented. Serositis was defined as pleurisy or pericarditis. Anaemia was defined when the haemoglobin was less than $12 \mathrm{~g} / \mathrm{dl}$ in women and $13 \mathrm{~g} / \mathrm{dl}$ in men according to the WHO definition [35].

The disease activity of SLE was assessed by 1 rheumatologist using the SLEDAI-2K and the physician's global assessment (PGA) (range $0-3.0$ ) at baseline and each visit $[33,36]$. Organ damage of each patient was determined by the SLICC/ACR Damage Index (SDI) at baseline [37]. The daily prednisone (or equivalent) dose, and hydroxychloroquine (HCQ) and IMs usage at baseline and each visit were also collected.

\section{LLDAS}

The definitions of LLDAS were: (a) SLEDAI-2K $\leq 4$, with no activity in major organ systems (renal, central nervous system, cardiopulmonary, vasculitis, fever), and no haemolytic anaemia or gastrointestinal active; (b) No new features of lupus disease activity compared with the previous assessment; (c) PGA $\leq 1$; (d) Prednisone dose $\leq 7.5 \mathrm{mg} /$ day; and (e) Well-tolerated standard maintenance doses of IMs [22]. The time to LLDAS was defined as the duration from baseline to the first follow-up visit achieving LLDAS.

\section{Statistical analysis}

Descriptive statistics were presented as the median (interquartile range (IQR) (25th percentile-75th percentile)) for continuous variables and numbers (frequency or percentages) for categorical variables. The Mann-Whitney $U$ test was performed for continuous variables and the chi-squared test was performed for categorical variables. The Kaplan-Meier curve was used to estimate the median (IQR) time to LLDAS and the annual cumulative probabilities of LLDAS achievement. Univariate and multivariable Cox proportional hazards model were used to identify predictors of time to LLDAS. Factors with $p$-value $\leq 0.1$ on univariate analysis then entered into the multivariate model and those that remained significant were retained in the models. The components of LLDAS (daily prednisone dose, SLEDAI and PGA) were added into the model for adjustment after performing the initial multivariate analysis. Finally, we investigated the baseline predictors of time to LLDAS and constructed a matrix model based on the identified independent predictors to present the time to LLDAS in patients with different characteristics at 
baseline. For better illustration, categorical variables would be converted to two-category or multiplecategory variables.

All analyses were performed with STATA version 15.1 (StataCorp, College Station, TX, USA) for Windows and a p-value of $<0.05$ was considered statistically significant.

\section{Results}

\section{Demographics and baseline characteristics}

The baseline characteristics of 574 patients with SLE included in this study were shown in Table 1. In these patients, 491 (85.5\%) were female and the median (IQR) age at onset was 28.8 (21.7-38.7) years. In these patients, 206 (35.9\%) had disease duration $\leq 1$ year and 229 (39.9\%) were treatment-naïve. The median (IQR) SLEDAI-2K and PGA at baseline were 8 (5-16) and 1.6 (1.0-1.9), respectively. At baseline, the

median (IQR) daily prednisone (or equivalent) dose was 50 (30-60) $\mathrm{mg}$ and 394 (68.9\%) patients received IMs.

\section{LLDAS achievement}

Patients were followed for a median (IQR) of 3.9 (2.1-6.5) years and 13 (9-20) visits. During follow-up, 435 (75.8\%) patients achieved LLDAS at least once. The baseline characteristics and the comparison between patients who achieved and did not achieve LLDAS during follow-up were shown in Table 1. The patients who achieved LLDAS had younger age at disease onset $(p=0.027)$, shorter disease duration $(p=0.004)$, higher frequency of treatment-naïve $(p<0.001)$, lower frequency of nephritis $(p=0.005)$, lower SDI $(p=0.004)$, less IMs usage $(p=0.005)$, and lower level of SLEDAI $(p<0.001)$ and PGA $(p=0.010)$ at baseline compared with those who never achieved LLDAS during follow up.

The median (IQR) time to LLDAS was $20.5(13.2,40.2)$ months and the cumulative probabilities of achieving LLDAS at 1, 2, 3, 5 and 10 follow-up years were $19.8 \%, 57.6 \%, 72.0 \%, 85.1 \%$ and $98.0 \%$, respectively. The Kaplan-Meier curve for time to LLDAS was illustrated in Figure 1.

\section{Predictors of time to LLDAS}

The predictors at baseline of time to LLDAS were identified by the univariable and multivariable Cox regression analyses.

In univariable analysis, baseline variables including male, age at disease onset, early SLE, treatmentnaïve, complicating with SS, arthritis and HCQ prescription were positively associated with LLDAS achievement, while nephritis, serositis and hypocomplementemia, high SLEDAI, PGA and SDI, as well as IMs prescription were negatively associated with LLDAS achievement (Table 2).

In multivariable Cox regression analysis, older age at disease onset (HR 1.010, $p=0.005)$, treatment-naïve (HR 1.346, $p=0.003$ ) and HCQ prescription at baseline (HR 1.638, $p<0.001)$ were identified as positive 
predictors of achieving LLDAS, while nephritis at baseline (HR 0.766, $p=0.009)$ was detected as a negative predictor of LLDAS achievement (Table 3, model 1). The older age at disease onset, treatmentnaïve and HCQ prescription remained significantly associated with a shorter time to LLDAS after adjusted by daily prednisone dose, SLEDAI and PGA. Moreover, high SLEDAI and PGA were negatively associated with a longer time to LLDAS (Table 3, model 2 and model 3 ).

\section{Matrix model}

Finally, we constructed a matrix model for time to LLDAS based on the identified independent factors associated with time to LLDAS, including age at disease onset, treatment-naïve and PGA (Figure 2). The numbers in each cell of the matrix model represented the median (IQR) time to LLDAS of patients with respective characteristics. For example, the median (IQR) time to LLDAS was 18.0 (13.0-32.9) months for treatment-naïve patients with age $\leq 30$ years at disease onset and PGA 1.1-2.0 at baseline.

\section{Discussions}

This is the first study to estimate the time to LLDAS and the predictors of time to LLDAS in the Asian population. Furthermore, we used a matrix model to illustrate the time to LLDAS in patients with different baseline characteristics, aiming to provide references to the future clinical trials and the clinical practice.

This study demonstrated that LLDAS is attainable as a treatment target for Chinese patients with SLE. In our SLE cohort, the time to LLDAS was 1.7 years, which was longer than that in the Johns Hopkins Lupus Cohort (1.1 years) mainly consisting of Caucasian and African-American patients [26]. The difference may be partly due to the different disease activity at baseline. In their cohort, $50.7 \%$ of patients had PGA $\leq 1$ and $53.8 \%$ had SLEDAI $\leq 4$ at baseline, while the percentages in our patients were only $28.7 \%$ and $24.0 \%$, respectively.

Our study confirmed that baseline disease activity could strongly influence the LLDAS achievement. Some previous studies found that patients with LLDAS $\geq 50 \%$ of follow-up time had a lower level of SLEDAl at baseline [14, 22, 23], and other studies found that baseline SLEDAI $\leq 4$ was a predictor of achieving LLDAS and maintaining LLDAS for 5 years $[15,26]$. The present study showed that patients with lower disease activity (by PGA or SLEDAI-2K) at baseline were more quickly to achieve LLDAS. Particularly, some components of SLEDAI including active nephritis, serositis and hypocomplementemia were found to be predictors of achieving LLDAS with longer time, while arthritis was found to be predictors of earlier LLDAS achievement.

Our study indicated that the age at disease onset of SLE could influence the LLDAS achievement. Previous researches had demonstrated that patients with juvenile-onset SLE had higher disease activity, received more intensive prednisone and IMs therapy, had more organ damage and a two-fold higher mortality rate, compared with adult-onset patients [38-42]. Recently, some studies reported that patients who were in LLDAS $\geq 50 \%$ time or observations during follow-up had older age at diagnosis of SLE [14, 
22, 23]. In the present study, patients with older age at disease onset were demonstrated to have shorter time to LLDAS after adjusting other factors, including daily prednisone dose, SLEDAI and PGA.

It should be noted that early treatment was a strong positive predictor for LLDAS achievement. Babaoglu et al found that patients with disease duration $\leq 1$ year had shorter time to LLDAS [26]. Our study confirmed the association and further found that treatment-naïve was also a positive predictor of LLDAS achievement. Moreover, patients with organ damage before recruitment were found to require longer time to achieve LLDAS. These evidences indicated early treatment could provide more opportunities for quick achievement of LLDAS.

Our study revealed that the patients who received HCQ as an initial treatment were able to achieve LLDAS faster. HCQ has been used in SLE for over half a century. Increasing evidences have been emerging to suggest the beneficial effects of HCQ, including reducing prednisone dose, decreasing disease activity, preventing lupus flares and organ damage accrual, and improving survival rate [43-49]. Babaoglu et al found that patients who received HCQ at baseline had a shorter time to LLDAS in univariable Cox model [26]. Our study further demonstrated that HCQ prescription was a strong independent predictor of shorter time to LLDAS, even after adjusted by disease activity factors. Apart from HCQ, other treatments were also evaluated in the present study. We found that those patients who used IMs at baseline required longer time to achieve LLDAS. A study from Tsang et al also showed that patients using IMs at baseline had a lower possibility of maintaining LLDAS $\geq 50 \%$ time during follow-up [14].

We found that complicating SS in SLE patients predicted a shorter time to LLDAS. A study by Baer et al showed that patients with both SLE and SS were a distinct subset with older age at SLE diagnosis and lower frequency of renal involvement [50], and our study revealed this overlap was also a factor of earlier achievement of LLDAS.

There were some limitations in this study. As an observational study, our data can hardly be used to evaluate the effect of different IMs on achieving LLDAS in SLE. Data from prospective intervention studies were needed to determine which medication could help to achieve LLDAS with less time. In addition, as all of the patients in this cohort were Chinese ethnicity, the conclusions may not be extrapolated to other ethnicities.

\section{Conclusions}

Our study proved that LLDAS is attainable as an early treatment target for SLE in Chinese patients. Older age at disease onset, treatment-naïve, lower disease activity and HCQ prescription at baseline are predictors of earlier LLDAS achievement.

\section{Abbreviations}

ACR: American College of Rheumatology; anti-dsDNA: anti-double stranded DNA; APS: antiphospholipid syndrome; HCQ: hydroxychloroquine; IM: immunosuppressant; IQR: interquartile range; LLDAS: Lupus 
Low Disease Activity State; PGA: physician's global assessment; PKUFHS: Peking University First Hospital SLE; SDI: SLICC/ACR Damage Index; SLE: systemic lupus erythematosus; SLEDAI-2K: SLE Disease Activity Index 2000; SLICC: Systemic Lupus International Collaborating Clinics; SS: Sjogren's syndrome.

\section{Declarations}

\section{Ethics approval and consent to participate}

This study was approved by the Ethics Committee of Peking University First Hospital (number: PKUFH2017[1284]) and informed consent was obtained from each patient at enrolment.

\section{Consent for publication}

Not applicable.

\section{Availability of data and materials}

The datasets used and/or analysed during the current study are available from the corresponding author on reasonable request.

\section{Competing interests}

The authors declare that they have no competing interests.

\section{Funding}

None.

\section{Authors' contributions}

Zhuoli Zhang and Yanjie Hao contributed to the design of the cohort and this study, and reviewed and revised the manuscript. Dai Gao contributed to the design of the study, to the collection, analysis and interpretation of the data, and drafted the manuscript. Lin Mu, Wenhui Xie, Yong Fan and Lanlan Ji contributed to the process of the data collection. All authors approved the final version of the manuscript and gave their agreement to the publication.

\section{Acknowledgements}

We would like to thank all the patients, nurses and rheumatologists who contributed to this study. We thank Yiwen Wang, for helping us refine the manuscript.

\section{References}

1. Gatto $M$, Zen $M$, laccarino L, Doria A: New therapeutic strategies in systemic lupus erythematosus management. Nat Rev Rheumatol 2019, 15(1):30-48. 
2. Jorge AM, Lu N, Zhang Y, Rai SK, Choi HK: Unchanging premature mortality trends in systemic lupus erythematosus: a general population-based study (1999-2014). Rheumatology (Oxford) 2018, 57(2):337-44.

3. Mak A, Cheung MW, Chiew HJ, Liu Y, Ho RC: Global trend of survival and damage of systemic lupus erythematosus: meta-analysis and meta-regression of observational studies from the 1950s to 2000s. Semin Arthritis Rheum 2012, 41(6):830-9.

4. Felten R, Sagez F, Gavand PE, Martin T, Korganow AS, Sordet C et al: 10 most important contemporary challenges in the management of SLE. Lupus Sci Med 2019, 6(1):e000303.

5. Lopez R, Davidson JE, Beeby MD, Egger PJ, Isenberg DA: Lupus disease activity and the risk of subsequent organ damage and mortality in a large lupus cohort. Rheumatology (Oxford) 2012, 51(3):491-8.

6. Petri M, Purvey $S$, Fang $H$, Magder LS: Predictors of organ damage in systemic lupus erythematosus: the Hopkins Lupus Cohort. Arthritis Rheum 2012, 64(12):4021-8.

7. van Vollenhoven RF, Mosca M, Bertsias G, Isenberg D, Kuhn A, Lerstrom K et al: Treat-to-target in systemic lupus erythematosus: recommendations from an international task force. Ann Rheum Dis 2014, 73(6):958-67.

8. van Vollenhoven R, Voskuyl A, Bertsias G, Aranow C, Aringer M, Arnaud L et al: A framework for remission in SLE: consensus findings from a large international task force on definitions of remission in SLE (DORIS). Ann Rheum Dis 2017, 76(3):554-61.

9. Schneider M: Target Therapy in SLE. Autoimmun Rev 2019, 18(1):21-4.

10. Dorner T, Furie R: Novel paradigms in systemic lupus erythematosus. Lancet 2019, 393(10188):234458.

11. Morand EF, Mosca M: Treat to target, remission and low disease activity in SLE. Best Pract Res Clin Rheumatol 2017, 31(3):342-50.

12. Wilhelm TR, Magder LS, Petri M: Remission in systemic lupus erythematosus: durable remission is rare. Ann Rheum Dis 2017, 76(3):547-53.

13. Morand EF: Connective tissue diseases: Remission in SLE - are we there yet? Nat Rev Rheumatol 2016, 12(12):696-8.

14. Tsang ASMW, Bultink IE, Heslinga M, Voskuyl AE: Both prolonged remission and Lupus Low Disease Activity State are associated with reduced damage accrual in systemic lupus erythematosus. Rheumatology (Oxford) 2017, 56(1):121-8.

15. Tani C, Vagelli R, Stagnaro C, Carli L, Mosca M: Remission and low disease activity in systemic lupus erythematosus: an achievable goal even with fewer steroids? Real-life data from a monocentric cohort. Lupus Sci Med 2018, 5(1):e000234.

16. Petri M, Magder LS: Comparison of Remission and Lupus Low Disease Activity State in Damage Prevention in a United States Systemic Lupus Erythematosus Cohort. Arthritis Rheumatol 2018, 70(11):1790-5. 
17. Parodis I, Nikpour M: How to use the Lupus Low Disease Activity State (LLDAS) in clinical trials. Ann Rheum Dis 2019.

18. Oon S, Huq M, Golder V, Ong PX, Morand EF, Nikpour M: Lupus Low Disease Activity State (LLDAS) discriminates responders in the BLISS-52 and BLISS-76 phase III trials of belimumab in systemic lupus erythematosus. Ann Rheum Dis 2019, 78(5):629-33.

19. Morand EF, Trasieva T, Berglind A, Illei GG, Tummala R: Lupus Low Disease Activity State (LLDAS) attainment discriminates responders in a systemic lupus erythematosus trial: post-hoc analysis of the Phase Ilb MUSE trial of anifrolumab. Ann Rheum Dis 2018, 77(5):706-13.

20. Tselios K, Gladman DD, Urowitz MB: How can we define low disease activity in systemic lupus erythematosus? Semin Arthritis Rheum 2019, 48(6):1035-40.

21. Durcan L, O'Dwyer T, Petri M: Management strategies and future directions for systemic lupus erythematosus in adults. Lancet 2019, 393(10188):2332-43.

22. Franklyn K, Lau CS, Navarra SV, Louthrenoo W, Lateef A, Hamijoyo L et al: Definition and initial validation of a Lupus Low Disease Activity State (LLDAS). Ann Rheum Dis 2016, 75(9):1615-21.

23. Golder V, Kandane-Rathnayake R, Huq M, Nim HT, Louthrenoo W, Luo SF et al: Lupus low disease activity state as a treatment endpoint for systemic lupus erythematosus: a prospective validation study. The Lancet Rheumatology 2019, 1(2):e95-e102.

24. Zen M, laccarino L, Gatto M, Saccon F, Larosa M, Ghirardello A et al: Lupus low disease activity state is associated with a decrease in damage progression in Caucasian patients with SLE, but overlaps with remission. Ann Rheum Dis 2018, 77(1):104-10.

25. Piga M, Floris A, Cappellazzo G, Chessa E, Congia M, Mathieu A et al: Failure to achieve lupus low disease activity state (LLDAS) six months after diagnosis is associated with early damage accrual in Caucasian patients with systemic lupus erythematosus. Arthritis Res Ther 2017, 19(1):247.

26. Babaoglu H, Li J, Goldman D, Magder LS, Petri M: Time to Lupus Low Disease Activity State in the Hopkins Lupus Cohort: Role of African-American Ethnicity. Arthritis Care Res (Hoboken) 2019.

27. Samanta A, Feehally J, Roy S, Nichol FE, Sheldon PJ, Walls J: High prevalence of systemic disease and mortality in Asian subjects with systemic lupus erythematosus. Ann Rheum Dis 1991, 50(7):4902.

28. Stoll T, Seifert B, Isenberg DA: SLICC/ACR Damage Index is valid, and renal and pulmonary organ scores are predictors of severe outcome in patients with systemic lupus erythematosus. $\mathrm{Br} \mathrm{J}$ Rheumatol 1996, 35(3):248-54.

29. Connelly K, Morand EF, Hoi AY: Asian ethnicity in systemic lupus erythematosus: an Australian perspective. Intern Med J 2013, 43(6):618-24.

30. Golder V, Connelly K, Staples M, Morand E, Hoi A: Association of Asian ethnicity with disease activity in SLE: an observational study from the Monash Lupus Clinic. Lupus 2013, 22(13):1425-30.

31. Mok MY, Li WL: Do Asian patients have worse lupus? Lupus 2010, 19(12):1384-90. 
32. Jakes RW, Bae SC, Louthrenoo W, Mok CC, Navarra SV, Kwon N: Systematic review of the epidemiology of systemic lupus erythematosus in the Asia-Pacific region: prevalence, incidence, clinical features, and mortality. Arthritis Care Res (Hoboken) 2012, 64(2):159-68.

33. Gladman DD, Ibanez D, Urowitz MB: Systemic lupus erythematosus disease activity index 2000. J Rheumatol 2002, 29(2):288-91.

34. Bombardier C, Gladman DD, Urowitz MB, Caron D, Chang CH: Derivation of the SLEDAl. A disease activity index for lupus patients. The Committee on Prognosis Studies in SLE. Arthritis Rheum 1992, 35(6):630-40.

35. Nutritional anaemias. Report of a WHO scientific group. World Health Organ Tech Rep Ser 1968, 405:5-37.

36. Petri M, Hellmann D, Hochberg M: Validity and reliability of lupus activity measures in the routine clinic setting. J Rheumatol 1992, 19(1):53-9.

37. Gladman D, Ginzler E, Goldsmith C, Fortin P, Liang M, Urowitz M et al: The development and initial validation of the Systemic Lupus International Collaborating Clinics/American College of Rheumatology damage index for systemic lupus erythematosus. Arthritis Rheum 1996, 39(3):363-9.

38. Brunner HI, Gladman DD, Ibanez D, Urowitz MD, Silverman ED: Difference in disease features between childhood-onset and adult-onset systemic lupus erythematosus. Arthritis Rheum 2008, 58(2):556-62.

39. Tucker LB, Uribe AG, Fernandez M, Vila LM, McGwin G, Apte M et al: Adolescent onset of lupus results in more aggressive disease and worse outcomes: results of a nested matched case-control study within LUMINA, a multiethnic US cohort (LUMINA LVII). Lupus 2008, 17(4):314-22.

40. Descloux E, Durieu I, Cochat P, Vital-Durand D, Ninet J, Fabien N et al: Influence of age at disease onset in the outcome of paediatric systemic lupus erythematosus. Rheumatology (Oxford) 2009, 48(7):779-84.

41. Livingston B, Bonner A, Pope J: Differences in clinical manifestations between childhood-onset lupus and adult-onset lupus: a meta-analysis. Lupus 2011, 20(13):1345-55.

42. Webb R, Kelly JA, Somers EC, Hughes T, Kaufman KM, Sanchez E et al: Early disease onset is predicted by a higher genetic risk for lupus and is associated with a more severe phenotype in lupus patients. Ann Rheum Dis 2011, 70(1):151-6.

43. Hsu CY, Lin YS, Cheng TT, Syu YJ, Lin MS, Lin HF et al: Adherence to hydroxychloroquine improves long-term survival of patients with systemic lupus erythematosus. Rheumatology (Oxford) 2018, 57(10):1743-51.

44. Floris A, Piga M, Mangoni AA, Bortoluzzi A, Erre GL, Cauli A: Protective Effects of Hydroxychloroquine against Accelerated Atherosclerosis in Systemic Lupus Erythematosus. Mediators Inflamm 2018, 2018:3424136.

45. Fasano S, Pierro L, Pantano I, ludici M, Valentini G: Longterm Hydroxychloroquine Therapy and Lowdose Aspirin May Have an Additive Effectiveness in the Primary Prevention of Cardiovascular Events in Patients with Systemic Lupus Erythematosus. J Rheumatol 2017, 44(7):1032-8. 
46. Ruiz-Irastorza G, Danza A, Khamashta M: Glucocorticoid use and abuse in SLE. Rheumatology (Oxford) 2012, 51(7):1145-53.

47. Ponticelli C, Moroni G: Hydroxychloroquine in systemic lupus erythematosus (SLE). Expert Opin Drug Saf 2017, 16(3):411-9.

48. Alarcon GS, McGwin G, Bertoli AM, Fessler BJ, Calvo-Alen J, Bastian HM et al: Effect of hydroxychloroquine on the survival of patients with systemic lupus erythematosus: data from LUMINA, a multiethnic US cohort (LUMINA L). Ann Rheum Dis 2007, 66(9):1168-72.

49. Akhavan PS, Su J, Lou W, Gladman DD, Urowitz MB, Fortin PR: The early protective effect of hydroxychloroquine on the risk of cumulative damage in patients with systemic lupus erythematosus. J Rheumatol 2013, 40(6):831-41.

50. Baer AN, Maynard JW, Shaikh F, Magder LS, Petri M: Secondary Sjogren's syndrome in systemic lupus erythematosus defines a distinct disease subset. J Rheumatol 2010, 37(6):1143-9.

\section{Tables}


Table 1 Baseline characteristics and comparisons of patients who achieved or not achieved LLDAS during follow-up

Characteristics

Female

Age at disease onset, years

Disease duration, years

Treatment-naïve

Comorbidities

Sjogren's syndrome

Antiphospholipid syndrome

\section{Clinical manifestations}

Fever

Mucosal ulcers

Alopecia

Rash

Raynaud's phenomenon

Arthritis

Myositis

Serositis

Neuropsychiatric manifestations

Nephritis

Haemolytic anaemia

Gastrointestinal involvement

\section{Laboratory tests}

Anti-dsDNA positive

Hypocomplementemia

Proteinuria

Haematuria
Overall

$\mathrm{n}=574$

491 (85.5)

28.8 (21.7-38.7)

$2.0(0.4-6.1)$

$229(39.9)$

$127(22.1)$

58 (10.1)

$77(13.4)$

55 (9.6)

$126(22.0)$

223 (38.9)

101 (17.6)

78 (13.6)

15 (2.6)

111 (19.3)

$39(6.8)$

$271(47.2)$

$26(4.5)$

$26(4.5)$

429 (74.7)

391 (68.1)

233 (40.6)

181 (31.5)
Achieved LLDAS Not achieved LLDAS $p$ value*

$\mathrm{n}=435$

$376(86.4)$

$115(82.7)$

0.280

$29.2(22.3-39.8)$

$26.4(20.3-36.3)$

0.027

$3.0(0.7-8.1)$

0.004

37 (26.6)

$<0.001$

$192(44.1)$

103 (23.7)

24 (17.3)

0.113

$44(10.1)$

$14(10.1)$

0.988

58 (13.3)

19 (13.7)

0.919

$43(9.9)$

$12(8.6)$

0.662

93 (21.4)

33 (23.7)

0.558

160 (36.8)

$63(45.3)$

0.072

77 (17.7)

24 (17.3)

0.907

64 (14.7)

$14(10.1)$

0.165

10 (2.3)

5 (3.6)

0.404

77 (17.7)

34 (24.5)

0.079

27 (6.2)

$12(8.6)$

0.322

191 (43.9)

80 (57.6)

0.005

$20(4.6)$

$6(4.3)$

0.890

17 (3.9)

9 (6.5)

0.205

$323(74.3)$

106 (76.3)

0.636

$290(66.7)$

101 (72.7)

0.187

160 (36.8)

83 (52.5)

0.001

$126(29.0)$

55 (39.6)

0.019 


\begin{tabular}{|c|c|c|c|c|}
\hline Sterile pyuria & $126(22.0)$ & $73(16.8)$ & $53(38.1)$ & $<0.001$ \\
\hline Urinary casts & $81(14.1)$ & $55(12.6)$ & $26(18.7)$ & 0.074 \\
\hline Anaemia & $297(51.7)$ & $220(50.6)$ & 77 (55.4) & 0.322 \\
\hline Leukopenia & 129 & $104(23.9)$ & 25 (18.0) & 0.145 \\
\hline Thrombocytopenia & $108(18.8)$ & $80(18.4)$ & $28(20.1)$ & 0.645 \\
\hline \multicolumn{5}{|l|}{ Scores } \\
\hline SLEDAI & $8(5-16)$ & $8(4-16)$ & $11(6-20)$ & $<0.001$ \\
\hline PGA & $1.6(1.0-1.9)$ & $1.6(0.9-1.8)$ & $1.6(1.2-2.2)$ & 0.010 \\
\hline SDI & $0(0-2)$ & $0(0-1)$ & $1(0-2)$ & 0.004 \\
\hline \multicolumn{5}{|l|}{ Treatments } \\
\hline Daily prednisone (or equivalent) dose & $50(30-60)$ & $50(30-60)$ & $45(20-60)$ & 0.929 \\
\hline HCQ & $473(82.4)$ & $362(83.2)$ & 111 (79.9) & 0.365 \\
\hline Immunosuppressants & $395(68.8)$ & $286(65.7)$ & 109 (78.4) & 0.005 \\
\hline Cyclophosphamide & $134(23.3)$ & $96(22.1)$ & $38(27.3)$ & 0.201 \\
\hline Mycophenolate mofetil & $122(21.3)$ & $83(19.1)$ & $39(28.1)$ & 0.024 \\
\hline Methotrexate & $58(10.1)$ & $45(10.3)$ & $13(9.4)$ & 0.735 \\
\hline Azathioprine & $46(8.0)$ & $33(7.6)$ & $13(9.4)$ & 0.504 \\
\hline Leflunomide & $35(6.1)$ & $27(6.2)$ & $8(5.8)$ & 0.846 \\
\hline Cyclosporine A & $17(3.0)$ & $15(3.4)$ & $2(1.4)$ & 0.224 \\
\hline
\end{tabular}

Values in the table are median (interquartile range: 25th-75th) or number (\%).

LLDAS Lupus Low Disease Activity State, SLEDAI-2K Systemic Lupus Erythematosus Disease Activity Index 2000, PGA physician's global assessment, SDI Systemic Lupus International Collaborating Clinics/ACR Damage Index, anti-dsDNA anti-double stranded DNA, $H C Q$ hydroxychloroquine.

\footnotetext{
*Mann-Whitney U test for continuous variables, and chi-squared test for categorical variables. Numbers in bold font indicate statistical significance for $p<0.05$.
} 
Table 2 Baseline variables associated with LLDAS achievement based on univariable Cox model

\begin{tabular}{|c|c|c|}
\hline Characteristics & HR $(95 \% \mathrm{CI})$ & $p$ value ${ }^{*}$ \\
\hline Female & $0.728(0.552-0.959)$ & 0.024 \\
\hline Age at disease onset, years & $1.011(1.005-1.018)$ & 0.001 \\
\hline Early SLE (disease duration $\leq 1$ year) & $1.401(1.154-1.702)$ & 0.001 \\
\hline Treatment-naïve & $1.505(1.243-1.823)$ & $<0.001$ \\
\hline \multicolumn{3}{|l|}{ Comorbidities } \\
\hline Sjogren's syndrome & $1.401(1.121-1.750)$ & 0.003 \\
\hline Antiphospholipid syndrome & $0.871(0.637-1.189)$ & 0.384 \\
\hline \multicolumn{3}{|l|}{ Clinical manifestations } \\
\hline Fever & $1.031(0.782-1.360)$ & 0.829 \\
\hline Mucosal ulcers & $1.217(0.888-1.667)$ & 0.223 \\
\hline Alopecia & $1.025(0.815-1.290)$ & 0.831 \\
\hline Rash & $0.959(0.788-1.165)$ & 0.671 \\
\hline Raynaud's phenomenon & $0.883(0.690-1.130)$ & 0.324 \\
\hline Arthritis & $1.400(1.072-1.828)$ & 0.013 \\
\hline Myositis & $0.832(0.444-1.558)$ & 0.566 \\
\hline Serositis & $0.764(0.597-0.978)$ & 0.033 \\
\hline Neuropsychiatric manifestations & $0.736(0.498-1.087)$ & 0.124 \\
\hline Nephritis & $0.741(0.613-0.896)$ & 0.002 \\
\hline Haemolytic anaemia & $1.031(0.658-1.616)$ & 0.894 \\
\hline Gastrointestinal involvement & $0.685(0.421-1.116)$ & 0.129 \\
\hline \multicolumn{3}{|l|}{ Laboratory tests } \\
\hline Anti-dsDNA positive & $0.907(0.732-1.126)$ & 0.377 \\
\hline Hypocomplementemia & $0.830(0.680-1.014)$ & 0.068 \\
\hline Proteinuria & $0.694(0.571-0.845)$ & $<0.001$ \\
\hline Haematuria & $0.796(0.647-0.980)$ & 0.032 \\
\hline Sterile pyuria & $0.558(0.433-0.718)$ & $<0.001$ \\
\hline Urinary casts & $0.722(0.544-0.959)$ & 0.025 \\
\hline Anaemia & $0.929(0.769-1.122)$ & 0.444 \\
\hline
\end{tabular}




\section{Scores}

SLEDAI

$0.979(0.968-0.991)$ $<0.001$

PGA

$0.833(0.730-0.952)$ 0.007

SDI $0.884(0.816-0.959)$ 0.003

\section{Treatments}

Daily prednisone (or equivalent) dose, $\mathrm{mg} / \mathrm{d}$

$0.998(0.995-1.002)$

HCQ

$1.734(1.342-2.241)$

$<0.001$

Immunosuppressants

$0.726(0.595-0.885)$

0.002

LLDAS Lupus Low Disease Activity State, HR hazard ratio, CI confidence interval, SLEDAI-2K Systemic

Lupus Erythematosus Disease Activity Index 2000, PGA physician's global assessment, SDI Systemic Lupus International Collaborating Clinics/ACR Damage Index, anti-dsDNA anti-double stranded DNA, HCQ hydroxychloroquine.

${ }^{*}$ Numbers in bold font indicate statistical significance for $p<0.05$. 
Table 3 Baseline variables associated with LLDAS achievement based on multivariable Cox models

\begin{tabular}{|c|c|c|c|c|c|c|}
\hline \multirow[t]{2}{*}{ Characteristics } & \multicolumn{2}{|c|}{ Model 1} & \multicolumn{2}{|c|}{ Model 2} & \multicolumn{2}{|c|}{ Model 3} \\
\hline & HR (95\% CI) & $p$ value & HR (95\% CI) & $p$ value & HR (95\% CI) & $p$ value \\
\hline \multirow[t]{2}{*}{ Age at disease onset, years } & $1.010(1.003-$ & 0.005 & 1.009 (1.002- & 0.010 & $1.010(1.003-$ & 0.004 \\
\hline & 1.016) & & 1.016) & & $1.017)$ & \\
\hline \multirow[t]{2}{*}{ Treatment-naïve } & $1.346(1.105-$ & 0.003 & $1.425(1.161-$ & 0.001 & $1.484(1.204-$ & $<0.001$ \\
\hline & 1.641) & & 1.749) & & 1.830) & \\
\hline \multirow[t]{2}{*}{ Nephritis } & $0.776(0.641-$ & 0.009 & $1.066(0.820-$ & 0.634 & $0.925(0.737-$ & 0.498 \\
\hline & $0.939)$ & & 1.385) & & $1.160)$ & \\
\hline \multirow[t]{2}{*}{ SLEDAI } & & & $0.968(0.950-$ & 0.001 & & \\
\hline & & & $0.987)$ & & & \\
\hline \multirow[t]{2}{*}{ PGA } & & & & & $0.685(0.551-$ & 0.001 \\
\hline & & & & & $0.853)$ & \\
\hline Daily prednisone (or equivalent) & & & $1.003(0.998-$ & 0.266 & $1.005(0.999-$ & 0.093 \\
\hline dose, $\mathrm{mg} / \mathrm{d}$ & & & 1.007) & & 1.010) & \\
\hline \multirow[t]{2}{*}{ HCQ } & $1.638(1.263-$ & $<0.001$ & $1.713(1.318-$ & $<0.001$ & 1.664 (1.284- & $<0.001$ \\
\hline & 2.123) & & $2.225)$ & & $2.157)$ & \\
\hline
\end{tabular}

In model 1, the components of LLDAS (daily prednisone dose, SLEDAI and PGA) were not included into the model; In the following models, SLEDAI (model 2) or PGA (model 3) was respectively added into the corresponding model with daily prednisone dose for adjustment. Of note, to avoid the collinearity, SLEDAI and PGA were not included in the same model.

LLDAS Lupus Low Disease Activity State, HR hazard ratio, CI confidence interval, SLEDAI-2K Systemic Lupus Erythematosus Disease Activity Index 2000, PGA physician's global assessment, SDI Systemic Lupus International Collaborating Clinics/ACR Damage Index, anti-dsDNA anti-double stranded DNA, HCQ hydroxychloroquine.

\section{Figures}




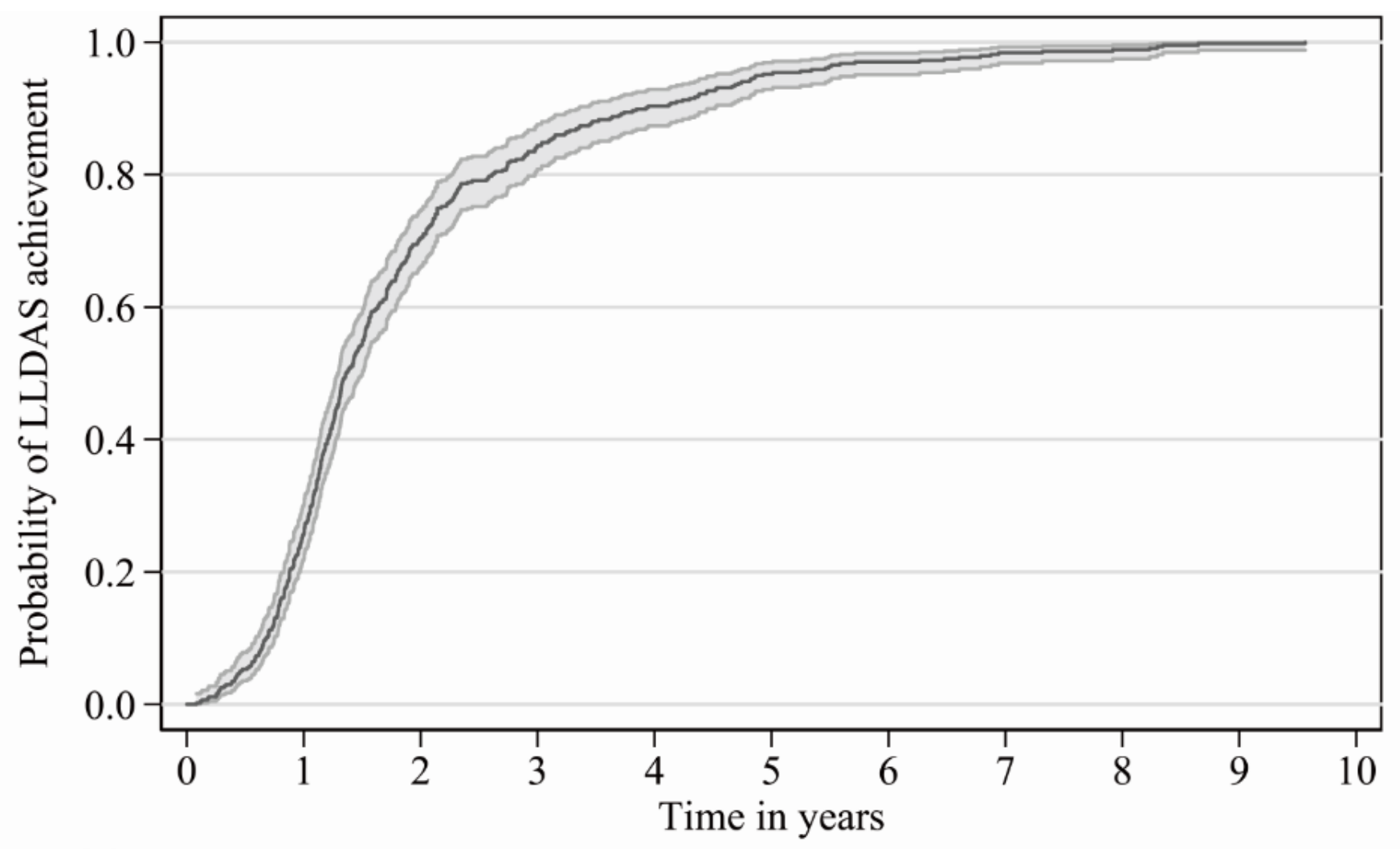

Number at risk

$\begin{array}{lllllllllll}435 & 323 & 129 & 68 & 42 & 21 & 13 & 7 & 5 & 1 & 0\end{array}$

Figure 2

Kaplan-Meier curve for time to Lupus Low Disease Activity State (LLDAS) during 10-year follow-up.

\begin{tabular}{|c|c|c|c|c|c|c|}
\hline & & & e to LLDAS (mo & ths) & & \\
\hline \multirow{4}{*}{ Treatment-naïve } & & $12.9(6.6-27.8)$ & $15.9(13.3-24.1)$ & $20.9(13.7-41.6)$ & $>30$ years & \multirow{4}{*}{$\begin{array}{c}\text { Age at } \\
\text { disease onset }\end{array}$} \\
\hline & & $13.3(11.0-22.6)$ & $18.0(13.0-32.9)$ & $23.2(15.8-35.0)$ & $\leq 30$ years & \\
\hline & \multirow{2}{*}{ No } & $17.2(11.7-52.5)$ & $18.5(12.7-30.9)$ & $32.9(14.0-82.5)$ & $>30$ years & \\
\hline & & $20.7(9.4-50.2)$ & $27.5(16.3-63.0)$ & $54.2(19.4-114.8)$ & $\leq 30$ years & \\
\hline & & $0-1.0$ & $\begin{array}{l}1.1-2.0 \\
\text { PGA }\end{array}$ & $2.1-3.0$ & & \\
\hline
\end{tabular}

\section{Figure 4}

Matrix model for time to LLDAS. The numbers in each cell of the matrix model represent the median (IQR) time to LLDAS of patients with respective characteristics. SLEDAI-2K was excluded from the matrix model due to the high collinearity with PGA, while HCQ was not included in the matrix model for it was not an objective parameter of patients. Age at disease onset was divided to age at disease onset $\leq 30$ 
years and age at disease onset $>30$ years, while PGA was divided to 0-1.0, 1.1-2.0 and 2.1-3.0. Colour scheme: green $<18$ months, yellow $\geq 18$ months and $<24$ months, blue $\geq 24$ months and $<36$ months, red $\geq 36$ months. IQR interquartile range, LLDAS Lupus Low Disease Activity State, PGA physician's global assessment. 